\title{
Effect of Transition Metals Oxides on the Physical and Mechanical Properties of Sintered Tungsten Heavy Alloys
}

\author{
Ayman H. Elsayed ${ }^{1}$, Mohamed A. Sayed ${ }^{2}$, Osama M. Dawood ${ }^{2}$ and Walid M. Daoush ${ }^{3,4, *(\text { D }}$ \\ Central Metallurgical R\&D Institute (CMRDI), Helwan 11421, Egypt; ayman_elsayed_11@yahoo.com \\ 2 Department of Mechanical Engineering, Faculty of Engineering, Helwan University, Cairo 11795, Egypt; \\ bhlolmohamed@yahoo.com (M.A.S.); osamadawood@yahoo.com (O.M.D.) \\ 3 Department of Production Technology, Faculty of Technology and Education, Helwan University, \\ Cairo 11281, Egypt \\ 4 Department of Chemistry, College of Science, Imam Mohammad ibn Saud Islamic University (IMSIU), \\ Al Riyadh 11432, Saudi Arabia \\ * Correspondence: wmdaoush@imamu.edu.sa
}

Received: 19 August 2020; Accepted: 11 September 2020; Published: 17 September 2020

\begin{abstract}
The addition of transition element oxides to tungsten heavy alloys (WHAs) fabricated by powder metallurgy technique provides new materials with higher density and electrical conductivity, which may be adequate in some applications such as kinetic energy penetrators. Additionally, materials with higher electrical conductivity are required for electrical contact applications such as electrical discharge machining (EDM) electrode materials. WHAs were fabricated by compacting its mixed constituents followed by sintering. $\mathrm{Ni}, \mathrm{Co}$ and $\mathrm{Fe}$ are used as binding phases of the tungsten particles and oxides of $\mathrm{Zr}$, Ti and $\mathrm{Y}$ are used as oxide dispersing strengthening (ODS) agents of the sintered materials. The results show that all of the chosen factors (i.e., pressure of compaction process, temperature of sintering, type of binding material and type of oxide) have clear effects on all properties of ODS tungsten heavy alloy specimens. The density and electrical conductivity increase with the increase in sintering temperature. Hardness and compression strength were also measured to evaluate the mechanical properties of sintered samples.
\end{abstract}

Keywords: transition metal oxides; tungsten heavy alloys; oxide dispersing strengthening; density; electrical conductivity; compression strength

\section{Introduction}

Tungsten heavy alloys (WHAs) are a group of materials that provide a special combination of properties. For example, they provide sintered parts with high density, excellent mechanical properties and good corrosion resistance, and these properties are so attractive for different applications such as defense applications, radiation shielding manufacturing and civil applications. The microstructures in this type of composites typically consist of tungsten particles reinforced in a ductile matrix of a solid-solution alloy, such as Fe-Ni or Co-Ni [1-5]. Mechanical properties of tungsten heavy alloys are influenced by their microstructural features such as tungsten grain size, matrix volume fraction and W-W contiguity. Several investigations have explored the possibility of improving the mechanical properties by alloying addition, mechanical alloying and cyclic heat treatment. Among these methods, oxide dispersion strengthening (ODS) gained significant importance because of its potential in refining the $\mathrm{W}$ grain size [6].

Oxide dispersion-strengthened tungsten heavy alloys were studied and developed over the past four decades due to their unique properties. These alloys are processed by powder metallurgy 
technique using liquid-phase sintering method [4-8]. It involves the use of fine oxide dispersions in the alloy to achieve better mechanical properties. Previous research on ODS tungsten heavy alloys revealed that the properties of these alloys were affected by some of factors (i.e., pressure of compaction, temperature of sintering process, sintering time, type of binding material, and type of dispersed oxide) $[6,7,9-11]$. In order to improve the performance and properties of these alloys the optimization of the previous factors is a very important issue.

Therefore, the present work sought to find out the effect of parameters such as the pressure of compaction, temperature of sintering process, type of binding material and type of dispersed metal oxide on the properties of ODS tungsten heavy alloys by oxides of transition elements such as $\mathrm{Y}$, $\mathrm{Zr}$ and Ti. The optimizing of ODS tungsten heavy alloy properties through design of experiments allows a reduction in experimental trials, the improvement of a product's manufacturability, enhanced reliability, quality, and performance.

\section{Planning of Experiments}

\subsection{Selection of Orthogonal Array}

In this investigation, an experimental matrix was designed according to the Taguchi experimental design method. The Taguchi experimental design method was developed by utilizing the nature of robust design, which is an experimental method, to achieve product and process quality through designing in insensitivity to noise based on statistical principles. When a product or process is robust, its response is less influenced by the uncontrollable factors. However, the Taguchi philosophy is to design quality into the product rather than to inspect for it after its production. The quality of the product should be considered at the beginning i.e., during the design stage of the product development and should continue through the production process (off-line quality) [12].

\subsection{Executing Experimental Work}

Tungsten powder $(99.95 \%, 0.5-4 \mu \mathrm{m})$ purchased from Buffalo Tungsten, INC., Ni, $\mathrm{Fe}, \mathrm{Co}(99.7 \%$, $0.5-2 \mu \mathrm{m})$ purchased from Jin Sheng International Industrial LTD and $\mathrm{Y}_{2} \mathrm{O}_{3}(99.995 \%, 0.3-1 \mu \mathrm{m})$, $\mathrm{ZrO}_{2}(99.9 \%, 0.3-0.7 \mu \mathrm{m}), \mathrm{TiO}_{2}(99 \%, 0.1-0.2 \mu \mathrm{m})$ transition metal oxides powders purchased from Inframat Advanced Materials were utilized in this study. The as-received powders were characterized using a scanning electron microscope in order to investigate the size and shape of the initial powders. Tungsten alloys consisting of $91 \mathrm{wt} \%$ of $\mathrm{W}$ metal and $7 \mathrm{wt} \%$ of (Ni-Fe, Ni-Co or Ni-Fe-Co) metallic binder were reinforced with $2 \mathrm{wt} \%$ of $\mathrm{Y}_{2} \mathrm{O}_{3}, \mathrm{ZrO}_{2}$ or $\mathrm{TiO}_{2}$ transition metal oxide particles and were fabricated by powder metallurgy and sintering techniques according to the conditions determined by the Taguchi orthogonal array, as indicated in Table 1.

Table 1. The experiment conditions.

\begin{tabular}{cccc}
\hline Exp. No. & Samples Composition, $(\mathbf{w t} . \%)$ & Sintering Temperature, $\left({ }^{\circ} \mathbf{C}\right)$ & Compaction Pressure, $(\mathbf{M P a})$ \\
\hline 1 & $91 \mathrm{~W}-4.9 \mathrm{Ni}-2.1 \mathrm{Fe}-2 \mathrm{Y}_{2} \mathrm{O}_{3}$ & 1300 & 200 \\
\hline 2 & $91 \mathrm{~W}-4.9 \mathrm{Ni}-2.1 \mathrm{Co}-2 \mathrm{ZrO}_{2}$ & 1400 & 200 \\
\hline 3 & $91 \mathrm{~W}-4.9 \mathrm{Ni}-1.05 \mathrm{Fe}-1.05 \mathrm{Co}-2 \mathrm{TiO}_{2}$ & 1500 & 200 \\
\hline 4 & $91 \mathrm{~W}-4.9 \mathrm{Ni}-2.1 \mathrm{Co}-2 \mathrm{TiO}_{2}$ & 1300 & 400 \\
\hline 5 & $91 \mathrm{~W}-4.9 \mathrm{Ni}-1.05 \mathrm{Fe}-1.05 \mathrm{Co}-2 \mathrm{Y}_{2} \mathrm{O}_{3}$ & 1400 & 400 \\
\hline 6 & $91 \mathrm{~W}-4.9 \mathrm{Ni}-2.1 \mathrm{Fe}-2 \mathrm{ZrO}_{2}$ & 1500 & 400 \\
\hline 7 & $91 \mathrm{~W}-4.9 \mathrm{Ni}-1.05 \mathrm{Fe}-1.05 \mathrm{Co}-2 \mathrm{ZrO}_{2}$ & 1300 & 600 \\
\hline 8 & $91 \mathrm{~W}-4.9 \mathrm{Ni}-2.1 \mathrm{Fe}-2 \mathrm{TiO}_{2}$ & 1400 & 600 \\
\hline 9 & $91 \mathrm{~W}-4.9 \mathrm{Ni}-2.1 \mathrm{Co}-2 \mathrm{Y}_{2} \mathrm{O}_{3}$ & 1500 & 600 \\
\hline
\end{tabular}


The powders with specific chemical composition given in the orthogonal array were milled using ball milling for $24 \mathrm{~h}$ milling time in order to homogenize the mixtures and reduce the size of the particles by mechanical milling. The dry ball milling process was accomplished using SPEX $8000 \mathrm{M}$ MIXER/MILL using stainless steel balls (6 mm diameter) and a milling container made also of stainless steel with (10:1) ball-powder ratio. The milling operation was performed at a constant speed of $80 \mathrm{rpm}$. After milling, $0.5 \mathrm{wt} \%$ paraffin wax was mixed with the milled powders. Paraffin wax is a lubricant used to reduce the friction effect during the compaction process. After the lubricant was mixed with the milled powders, cold compaction of powders was achieved at room temperature and at compaction pressures of 200, 400, and $600 \mathrm{MPa}$ in order to study the compressibility of the pressed powders and its correlation with the sintering properties. The compacted specimens were divided into three groups, the first group was sintered at temperature of $1300^{\circ} \mathrm{C}$, the second one was sintered at $1400{ }^{\circ} \mathrm{C}$ and the third was sintered at $1500^{\circ} \mathrm{C}$ under vacuum for 1 hour and heating rate of $5^{\circ} \mathrm{C} / \mathrm{min}$.

Extensive metallographic studies were accomplished to assess the microstructure of the ODS tungsten heavy alloys using scanning electron microscopy (model JEOL-JSN-5410). The phase observation and the chemical compositions of the studied ODS tungsten heavy alloys were accomplished using XRD (model X, Pert PRO analytical with $\mathrm{Cu} \mathrm{k}_{\alpha}$ radiation, $\lambda=0.15406$ ).

The sintered density of the specimens was measured using the Archimedes principle and distilled water was chosen as a floating liquid, in which the sintered specimen was weighed in air and water separately. The electrical resistivity of the sintered materials was evaluated using Omega CL 8400 micro-ohmmeter at room temperature. The Vickers hardness values of the inspected sintered materials were measured along the cross-section surface of the sintered samples using a universal hardness system at a load of $30 \mathrm{Kg}$ for $15 \mathrm{~s}$. The compressive strength was also evaluated on cylindrical test specimens using UH-500, Shimadzu universal testing machine. The selected specimen area was $67.3 \mathrm{~mm}^{2}$ and the strain rate was $5 \mathrm{~mm} / \mathrm{min}$. The maximum compressive load for each specimen was obtained.

\section{Results and Discussion}

The experimental results were analyzed using Taguchi through Minitab software in order to determine the most significant factors and the optimal levels of selected factors [12].

\subsection{Microstructure Investigation}

The as-received powders were investigated to determine their particle size and shape. The micrographs that resulted from SEM of the studied $\mathrm{W}, \mathrm{Ni}, \mathrm{Fe}, \mathrm{Co}, \mathrm{Y}_{2} \mathrm{O}_{3}, \mathrm{ZrO}_{2}$, and $\mathrm{TiO}_{2}$ powders are shown in Figure $1 \mathrm{a}-\mathrm{g}$, respectively. It was observed from the results that the particles of the $\mathrm{W}$ powder have a particle shape of equiaxed grains with a size range of approximately from $500 \mathrm{~nm}$ to $4 \mu \mathrm{m}$. On the other hand, the constituents of the powders used to form the binder liquid phase, which is nickel, iron and/or cobalt, have a spherical shape and approximate sizes of $\sim 2 \mu \mathrm{m}$. However, the reinforced transition metal oxide of $\mathrm{Y}_{2} \mathrm{O}_{3}$ powder has a flake shape; $\mathrm{ZrO}_{2}$ powder has a rounded shape, and particle size of less than $\sim 3 \mu \mathrm{m}$; but the used $\mathrm{TiO}_{2}$ powder is very fine in the range of nanometer scale $\sim 200-500 \mathrm{~nm}$ with equiaxed grains.

From the above investigation, it may be concluded that the raw powders are characterized by various particle morphologies, such as spherical and irregular shapes with a clear variation in particle size, which improves the packing, flow, and compressibility of powders during cold compaction.

Figure 2 illustrates the SEM micrographs of the nine sintered samples (nine experiments) of ODS tungsten heavy alloys. The sintered samples were initially ground with silicon carbide paper up to 3000 grit paper finish and then polished using $\mathrm{Al}_{2} \mathrm{O}_{3}$. The dark grey zones in the micrographs refer to the matrix, while the white grey zones are the tungsten particles as shown by arrows. 

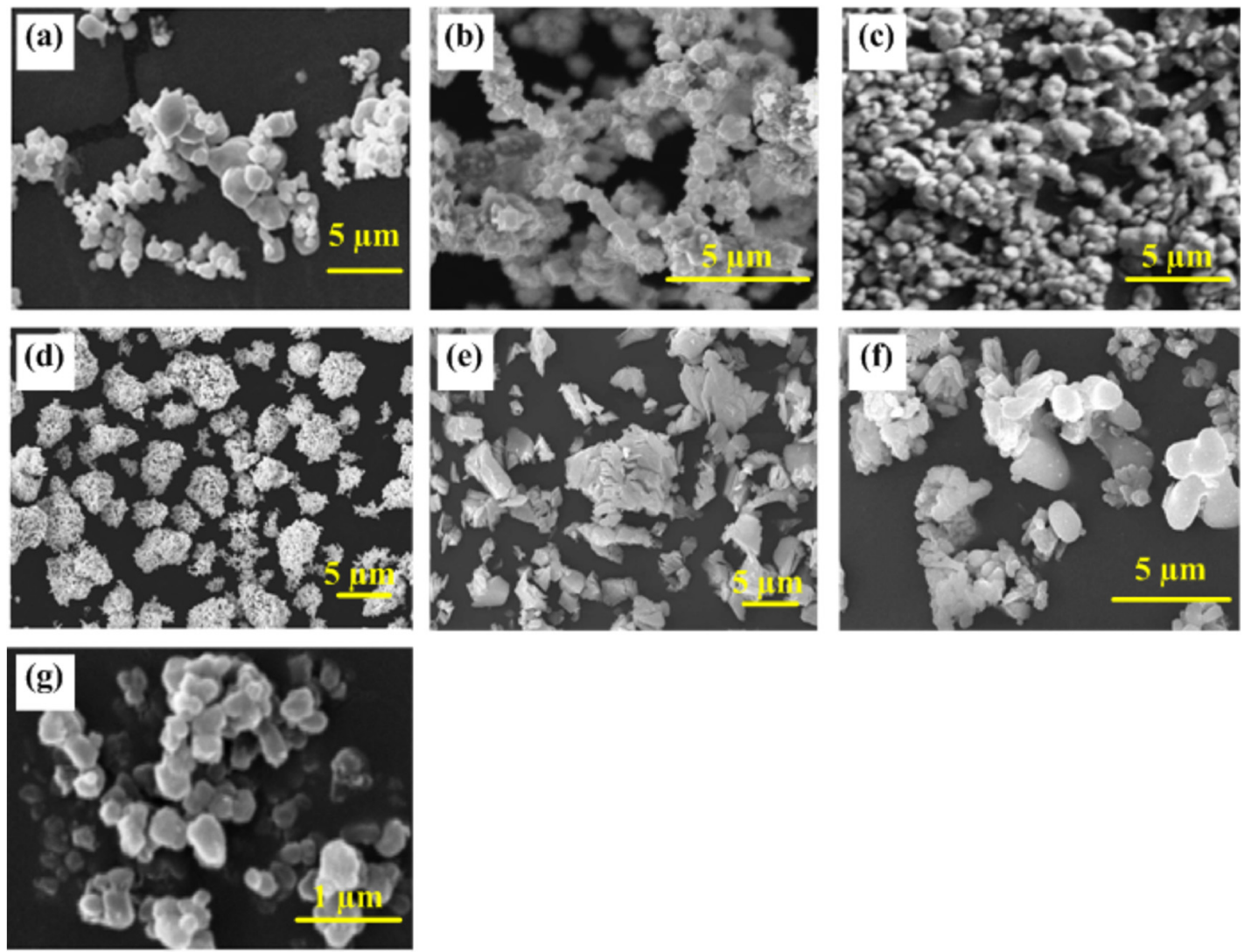

Figure 1. SEM images of the as received metals and rare metal oxide powders, where: (a) W, (b) Ni, (c) $\mathrm{Fe},(\mathbf{d}) \mathrm{Co},(\mathbf{e}) \mathrm{Y}_{2} \mathrm{O}_{3}$, (f) $\mathrm{ZrO}_{2}$, and (g) $\mathrm{TiO}_{2}$.
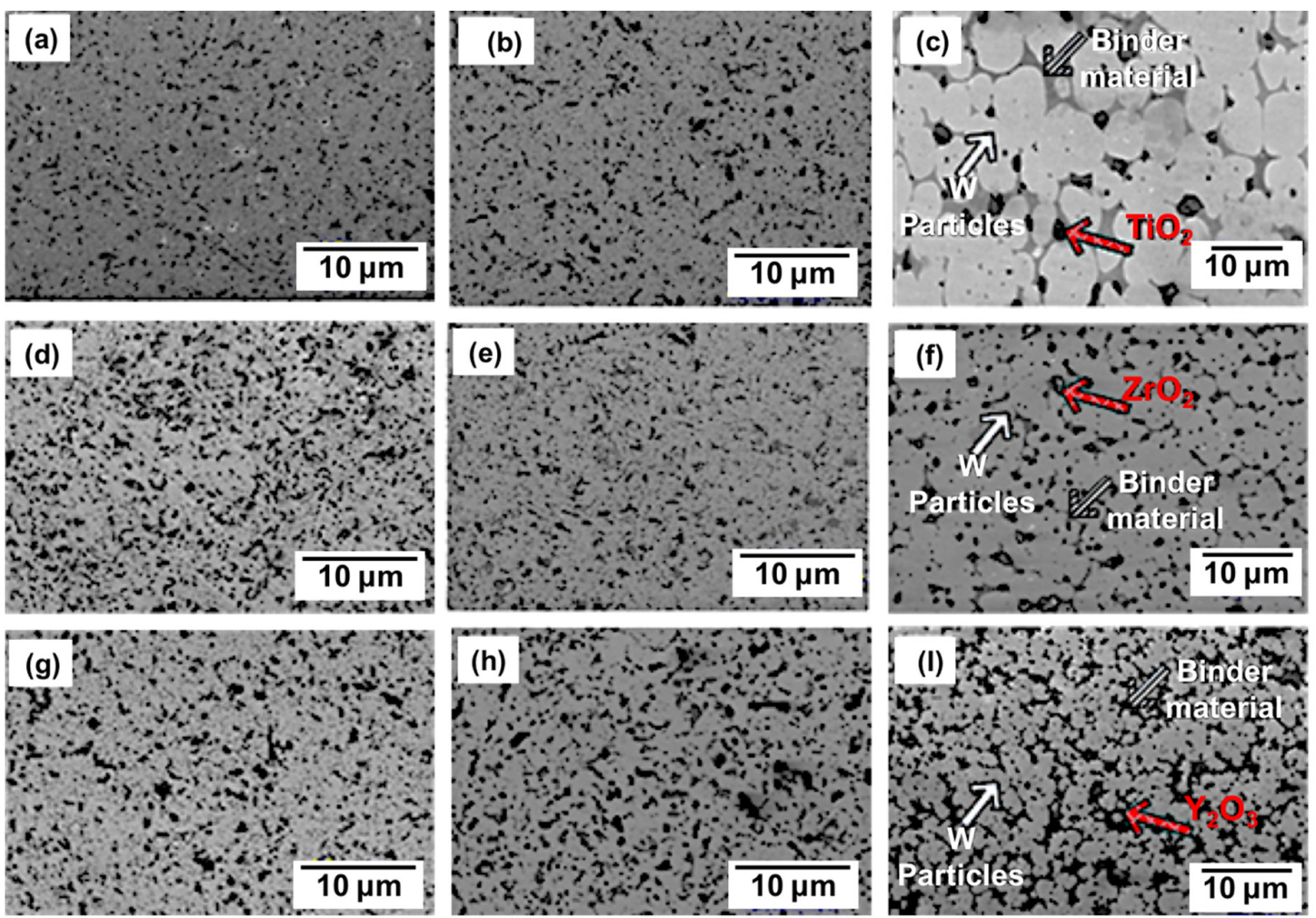

Figure 2. (a-I) Microstructures of oxide dispersing strengthening (ODS) tungsten heavy alloys by SEM numbered from one to nine according to the Taguchi orthogonal array, as listed in Table 1. 
It was observed from the microstructure in Figure 2 that the average size of tungsten grains in the samples ranges from 2 to $8 \mu \mathrm{m}$. This result is much finer than that of commercial one $(40-60 \mu \mathrm{m})$ in previous reported work [13]. This is due to the effect of the contribution of the additives of the reinforced transition metal oxides, which refine the microstructure of tungsten heavy alloys. These oxide particles prevent the metal oxide formation in the matrix and reduce the grain growth. In addition, it was reported that the transition metal oxide, such as $\mathrm{Y}_{2} \mathrm{O}_{3}$, is a type of oxide that can improve the sinterability of the tungsten compacts. During sintering, the oxide particles appear as an activator and the paths of atom movement are increased and hence, the $\mathrm{W}$ powder sinterability may be enhanced. Furthermore, the fine microstructure of $\mathrm{TiO}_{2}$ is due to the presence of the nanostructure $\mathrm{TiO}_{2}$ oxide particles $(\sim 200 \mathrm{~nm})$, which help in refining the microstructure. In addition, the oxide particles improve the densification process and decrease the porosity level by capturing the oxygen in the matrix. $[7,9,13,14]$. The results also show that the tungsten grains grow considerably into round globular shapes at higher sintering temperature (as seen in samples three, six, and nine). These samples were sintered through the liquid phase sintering mechanism at $1500{ }^{\circ} \mathrm{C}$. It is known that for liquid phase sintering, a liquid phase combined with solid particles of tungsten coexist at the sintering temperature. The presence of liquid phase at the sintering temperature improves the diffusion between adjacent particles and hence, increases bonding between particles and also enhances densification during sintering [15]. During liquid phase processing, dissolution of the liquid metallic binder phase occurs until a local equilibrium in the solid matrix is reached. When the matrix melts at around $1455^{\circ} \mathrm{C}$, it starts to diffuse through the solid tungsten grain structure by both diffusion and capillary forces. As the diffusion of the tungsten globules proceeds and free tungsten globules are formed, a fraction of each of the tungsten globules containing sharp edges are dissolved. During this stage, the median size of the tungsten globules decreases below the particle size of the original metal powders used. In the final stage, the growth of larger globules occurs at the same time as smaller globules are dissolved. The microstructure of samples sintered at $1500{ }^{\circ} \mathrm{C}$ supports the $\mathrm{W}$ particle growth through a "solution-reprecipitation" process during sintering, which agrees with previous reports [6,15-19].

The reinforced particles of the transition metal oxide have been preferentially positioned inside the matrix and located at the grain boundaries (black particles in Figure 3), which could be confirmed by the $\mathrm{X}$-ray mapping of the produced $\mathrm{TiO}_{2} / \mathrm{Ni}-\mathrm{Fe}-\mathrm{Co}-\mathrm{W}$, as shown in Figure 3.
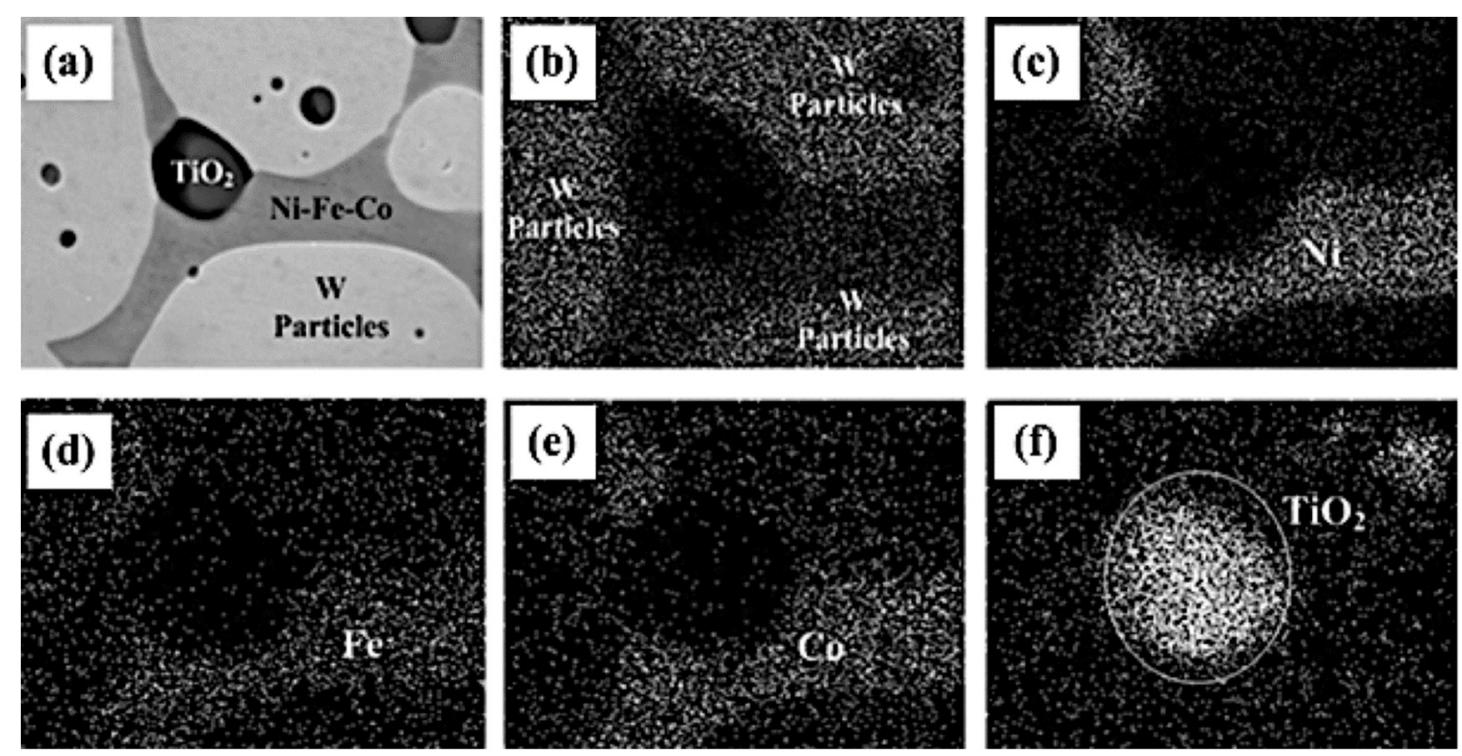

Figure 3. X-ray mapping of $\mathrm{TiO}_{2} / \mathrm{Ni}-\mathrm{Fe}-\mathrm{Co}-\mathrm{W}$ alloy using SEM-EDS, where: (a) $\mathrm{TiO}_{2} / \mathrm{Ni}-\mathrm{Fe}-\mathrm{Co}-\mathrm{W}$, (b) W particles, (c) $\mathrm{Ni}$, (d) $\mathrm{Fe},(\mathbf{e}) \mathrm{Co}$ and (f) $\mathrm{TiO}_{2}$ particles. 
X-ray diffraction analysis (XRD) was performed to identify the phase crystalline structures investigated by the SEM analysis and to determine the phase composition. The XRD investigations of the obtained ODS tungsten heavy alloys revealed that the first set of peaks belongs to the tungsten phase with body centered cubic (BCC) structure, as illustrated in Figure 4. Meanwhile, four weaker peaks, which represent $\mathrm{Ni}-\mathrm{W}$ solid solution crystalline phase, were observed. However, the minor elements cannot be detected by the X-ray diffraction analysis due to the limitations of the X-ray diffraction technique.

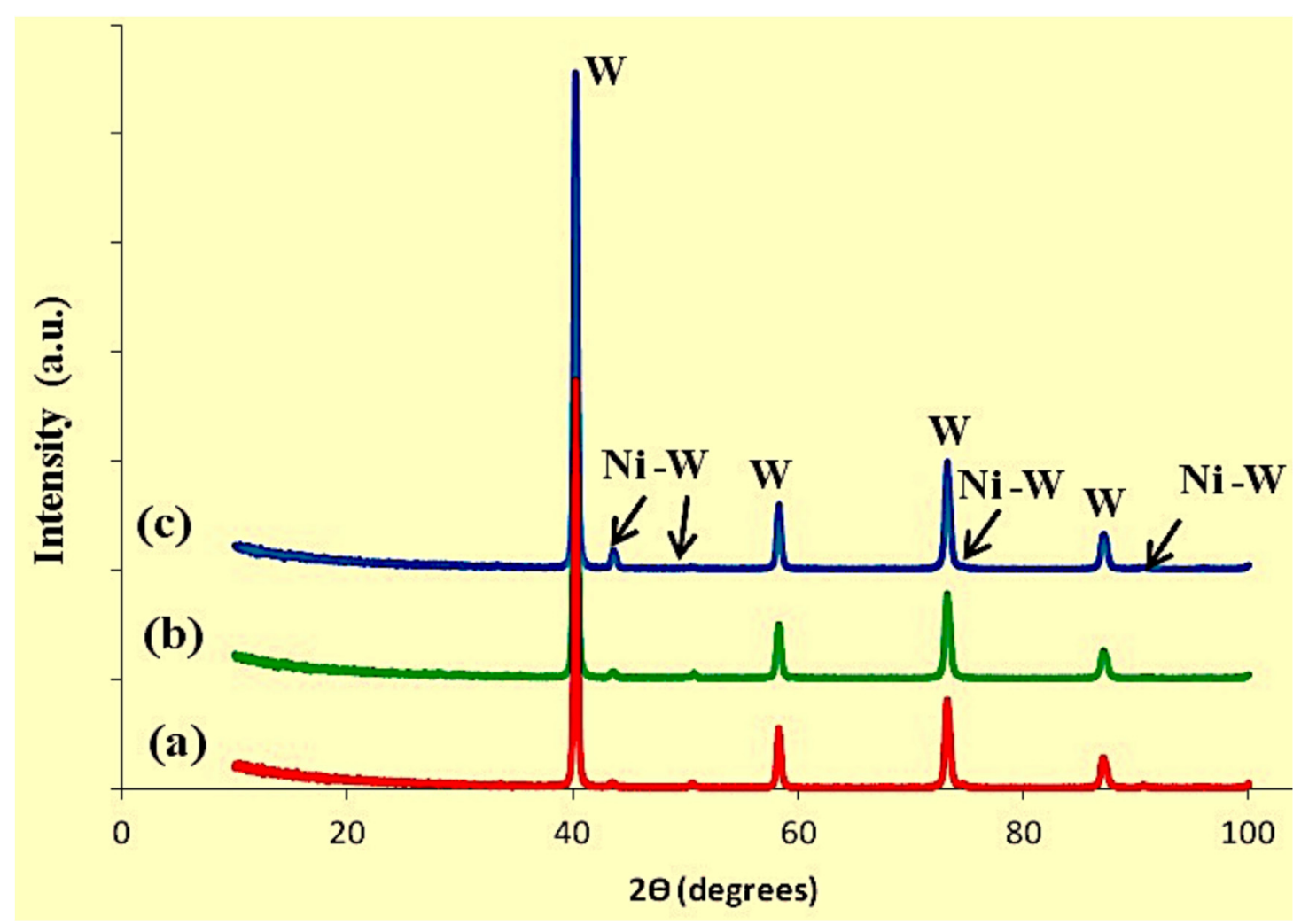

Figure 4. XRD patterns of the obtained ODS tungsten heavy alloys sintered materials, where: (a) W-Ni-Fe-Co-TiO 2 (sample no. three), (b) W-Ni-Fe- $\mathrm{ZrO}_{2}$ (sample no. six) and (c) W-Ni-Co- $\mathrm{Y}_{2} \mathrm{O}_{3}$ (sample no. nine).

At the onset of particles bonding, re-arrangement of particles and pore filling happens, and hence rapid densification of the compacts and formation of W-Ni solid solution occurs [19,20]. Due to the presence of nickel in the liquid phase during liquid phase sintering, the effect of nickel on the recrystallization of tungsten has been investigated by several researchers. Nickel has a noticeable effect on tungsten sinterability by largely decreasing the recrystallization temperature [21].

\subsection{Physical Properties Analysis Using Taguchi Method}

\subsubsection{Sintered Densities of Investigated Samples}

The relative densities of the alloys are presented in both Table 2 and Figure 5. It is clear from Figure 5 that the alloy density increases by increasing compaction pressure until $400 \mathrm{MPa}$ then decreases. This can be due to the highly dense green compact surfaces at $600 \mathrm{MPa}$, which leave no pores at their surface and prohibits the lubricants after evaporation and/or moisture from escaping while sintering. Consequently, the gases get entrapped inside the samples during sintering, forming porosity. Furthermore, the high values of pressure used in compaction may lead to more particle contact that 
reduces the movement of particles due to rearrangement during liquid phase sintering. This, in turn, lowers the sintering density [22].

Table 2. Experimental results.

\begin{tabular}{ccccc}
\hline Experiment & Relative & Electrical & Vickers & Compressive \\
\hline no. & Density $\%$ & Resistivity, $\boldsymbol{\mu} \Omega . c m$ & Hardness, Hv & Strength, MPa \\
\hline 1 & 88 & 0.128 & 242.3 & 845.3 \\
2 & 92 & 0.162 & 327.8 & 2048.9 \\
3 & 96.1 & 0.17 & 348.5 & 2057.8 \\
4 & 96.3 & 0.139 & 385.7 & 2005.3 \\
5 & 91.6 & 0.164 & 350.3 & 2057.5 \\
6 & 94.5 & 0.157 & 341.4 & 2052.5 \\
7 & 90.6 & 0.115 & 291.1 & 1772.4 \\
8 & 92.4 & 0.153 & 341.2 & 2029.7 \\
9 & 88.6 & 0.158 & 366.7 & 1995.6 \\
\hline
\end{tabular}

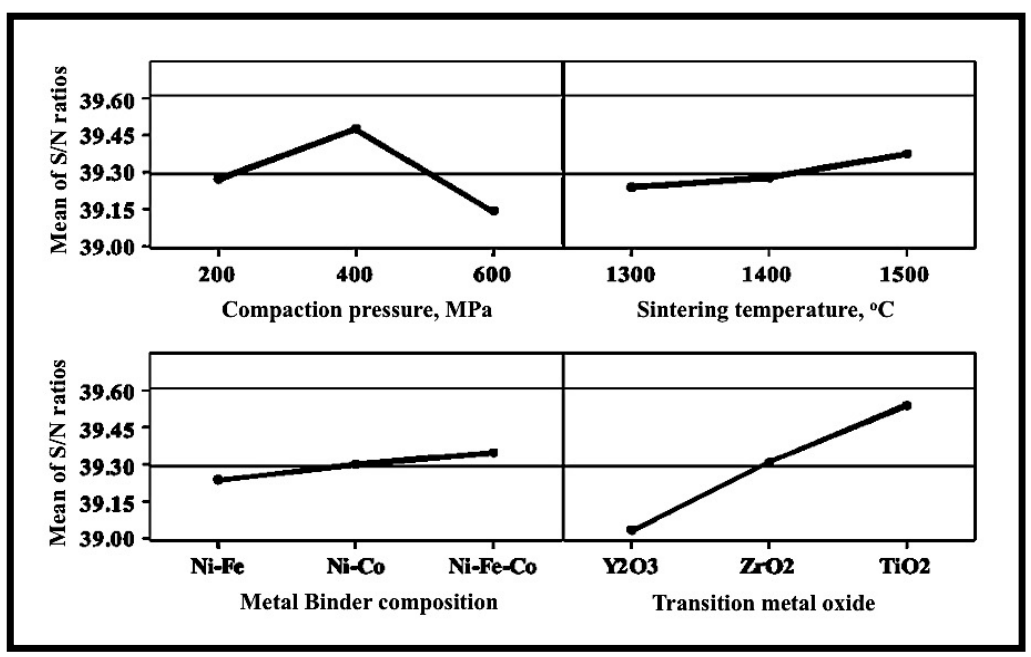

Figure 5. Mean of $\mathrm{S} / \mathrm{N}$ ratios for density of samples versus levels of input parameters.

Additionally, from Figure 5 it can be seen that the density is increased by increasing the temperature of sintering. This may be attributed to the increased fluidity of melt. As the sintering temperature increased, solubility and diffusivity of the edges of the tungsten particles in liquid phase are increased and also the coalescence of the small size tungsten globules are also increased, which caused porosity elimination and eventually increases density [22]. Therefore, by increasing density and eliminating porosity, grain growth occurred. Due to the removal of porosity during densification, grain motion happens at a higher rate and causes the growth of grains [15]. The micrographs of the investigated ODS tungsten heavy alloys (samples three, six and nine), as shown in Figure 2, shows the effect of liquid phase sintering temperature on the microstructure and sintered density of the investigated samples.

The results also show that the highest density was predictable at the metal binder phase of the composition Ni-Co-Fe. Previous studies show that the sintering of tungsten alloys can be enhanced by the existence of cobalt, as it prompts and increases the of rate of diffusion [8]. The existence of cobalt in the alloy allows solid-solution strengthening and eventually enhances interfacial strength between tungsten particles and the matrix [23].

After predicting the optimal density, the verification experiment was conducted in order to evaluate the difference between the measured and predicted values. The condition $A_{2} B_{3} C_{3} D_{3}$ of the optimal parameter combination of the Taguchi method was treated as a verification run. Three specimens were prepared under the optimal parameter set up in the study. The mean relative density of the verified specimens was $97.23 \pm 0.45 \%$. This result indicates that the selected control factor levels produced the 
best density. The variation between the predicted relative density and the verified relative density is about $1.01 \%$, which means that the predicted and verified values are close to each other.

\subsubsection{Electrical Conductivities of ODS Tungsten Heavy Alloys}

It is noticed from $\mathrm{S} / \mathrm{N}$ ratio analysis, as shown in Figure 6 and the values of the electrical resistivity listed in Table 2, that the electrical conductivity increases by increasing the sintering temperature. This can be attributed to the lower content of porosity at the higher sintering temperatures and also the presence of the transition metal oxides that reduce the porosity content due to its affinity to inhibit oxidation. As the porosity content increases, the electrical resistivity increases, and this leads to lower values of electrical conductivities [22]. Moreover, the electrical conductivity increases by increasing compaction pressure until $400 \mathrm{MPa}$ and then decrease at $600 \mathrm{MPa}$, which can be due to high porosity forming at higher compaction pressure.

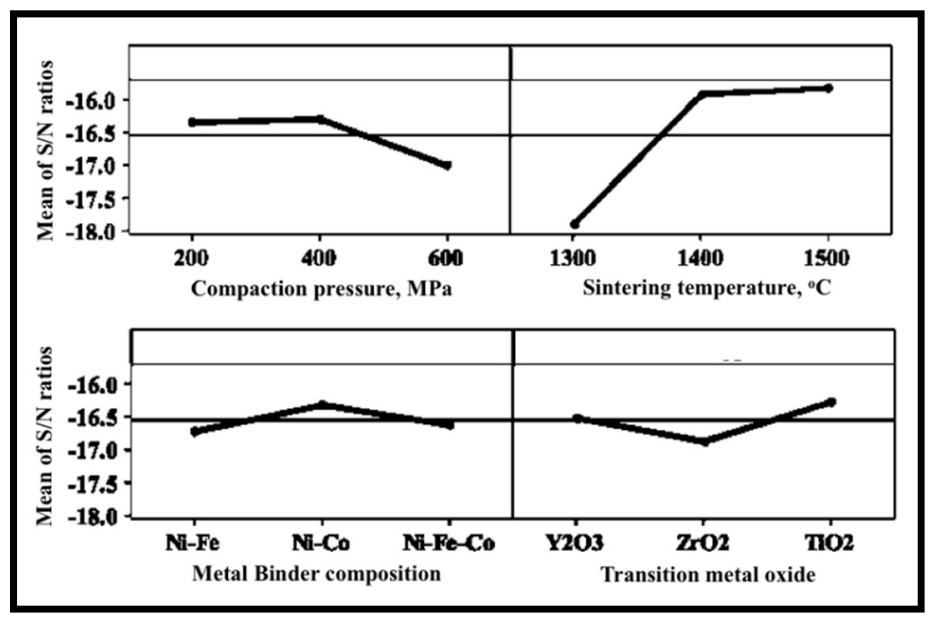

Figure 6. Mean of $\mathrm{S} / \mathrm{N}$ ratios for electrical conductivity of samples versus levels of input parameters.

The results also show that the $\mathrm{Ni}-\mathrm{Co}$ binder material and $\mathrm{TiO}_{2}$ produce maximum electrical conductivity for ODS tungsten heavy alloys. This may be attributed to higher densities of samples containing these elements.

In general, the electrical conductivity of powder metallurgy components is reduced by the presence of pores, powder surface contaminants or any non-conducting inclusions [24]. It is known that within solid materials the electric current arises from the flow of electrons. The value of the electrical conductivity strongly depends on the number of electrons, which can be shared in the conduction process. Meanwhile, when the current attains a specific value, there exists what is named "frictional forces". These frictional forces are attributed to the scattered electrons by faults in the crystal lattice, which includes the atoms of the vacancies, impurities, interstitial atoms, dislocations and the thermal vibrations of the atoms. Increasing the number of crystalline defects increases the resistivity because they act as centers to scatter the conducting electrons [25].

The verification experiment was conducted at the optimized factor levels $\mathrm{A}_{2} \mathrm{~B}_{3} \mathrm{C}_{2} \mathrm{D}_{3}$ by the Taguchi method. The value of electrical conductivity was calculated from the verified electrical resistivity. The electrical conductivity value for the verification experiment is measured to be $0.171 \pm 0.001 \mu \Omega^{-1} \mathrm{~cm}^{-1}$, which is in confidence interval of the predicted electrical conductivity $\left(0.173 \mu \Omega^{-1} \mathrm{~cm}^{-1}\right)$ where there is $1.15 \%$ difference between the predicted and verified electrical conductivity. 


\subsection{Mechanical Properties Analysis Using Taguchi Method}

\subsubsection{Hardness of ODS Tungsten Heavy Alloys}

The values of the Vickers hardness presented in Table 2 and Figure 7 indicates that the hardness of tungsten alloys increases by increasing compaction pressure until $400 \mathrm{MPa}$ then decrease at $600 \mathrm{MPa}$. Hardness is affected by the level of porosity where the hardness increases as the porosity content decreases. This is because high pressures hinder the evaporated lubricants (paraffin wax) and/or moisture from escaping during sintering and lead to pores being trapped in the sintered compacts [22].

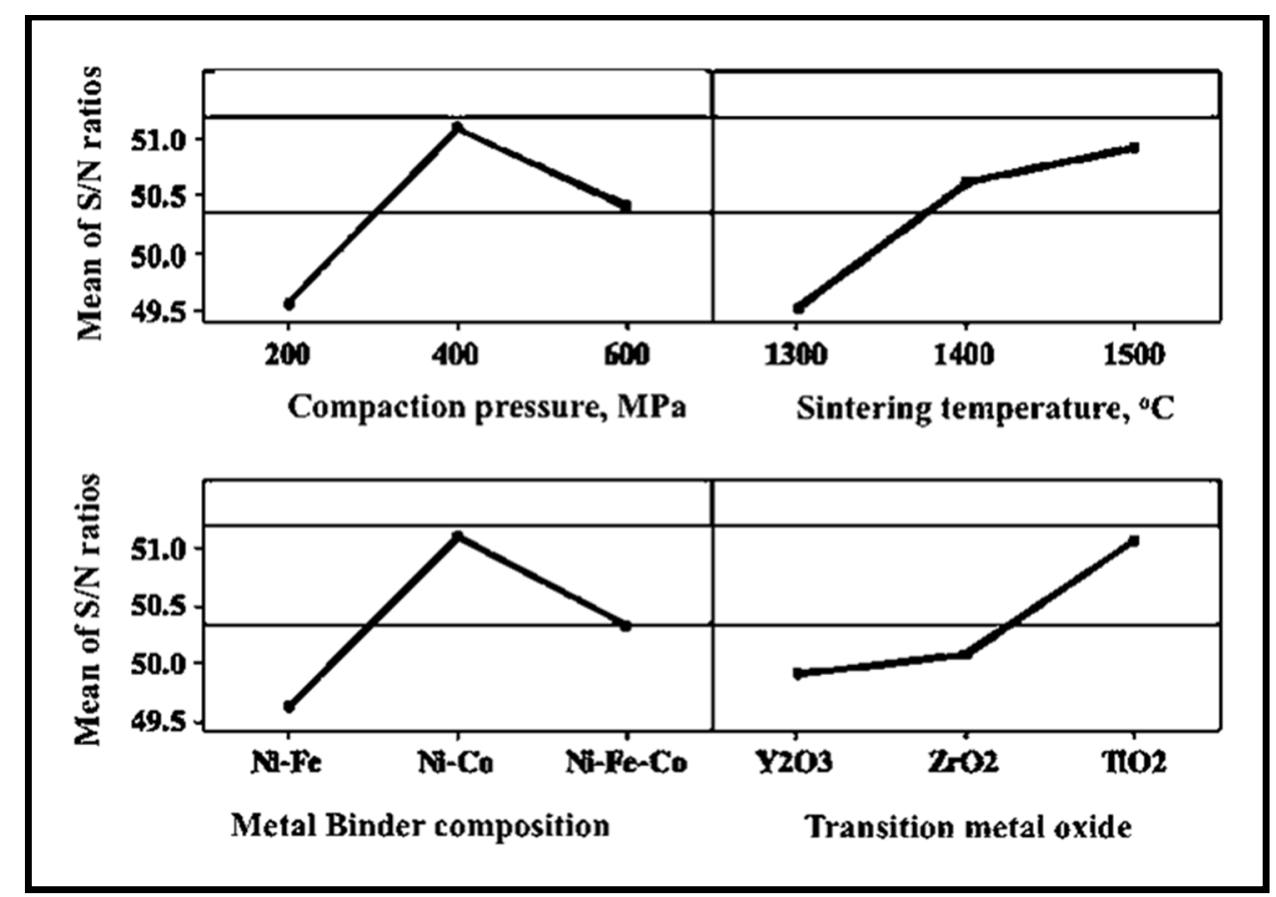

Figure 7. Mean of $\mathrm{S} / \mathrm{N}$ ratios for hardness of samples versus levels of input parameters.

Figure 7 also shows that the hardness increases by increasing the sintering temperature. This may be attributed to the increase in the sintered density and porosity elimination at high temperature during the liquid phase sintering [15]. The results of $\mathrm{S} / \mathrm{N}$ ratio analysis also showed that the optimal hardness was at Ni-Co binder material and this agrees with previous research [26], which showed that the mechanical properties of $\mathrm{W}-\mathrm{Ni}-\mathrm{Co}$ alloy containing $\mathrm{Ni}$ to Co ratios of two to nine are greater than the properties of $\mathrm{W}-\mathrm{Ni}-\mathrm{Fe}$ alloys. The response graph also showed that the optimal hardness is attained at the transition metal oxide type of $\mathrm{TiO}_{2}$. This is attributed to its highest hardness [7]. Compared to the three kinds of transition metal oxide particles, $\mathrm{TiO}_{2}$ has the most influence on hardness of ODS tungsten heavy alloys. It was discussed in previous reports that the presence of $\mathrm{Ti}$ or $\mathrm{TiO}_{2}$ yields significant grain refinement and thus improves hardness [14]. $\mathrm{TiO}_{2}$ offers excellent physical and chemical stability, which inhibits dislocation and grain growth during sintering. The samples one (W-Ni-Fe- $\mathrm{Y}_{2} \mathrm{O}_{3}$ ) and seven (W-Ni-Fe-Co-ZrO $\mathrm{Zr}_{2}$ ) have the lowest hardness values and the sample four $\left(\mathrm{W}-\mathrm{Ni}-\mathrm{Co}-\mathrm{TiO}_{2}\right)$ has the largest hardness value. Microstructures of these specimens, which contain the marks of hardness indentation, are presented in Figure 8. It was observed form the results that the diagonal size of the mark of indentation in samples one and seven is observed to be longer than that of sample four. This may be attributed to the fine structure of sample four and the presence of low porosity content, which increases the hardness. It may further be noted from Figure 8 that; sample one has high porosity content, which reduces the hardness value to the lowest level. 

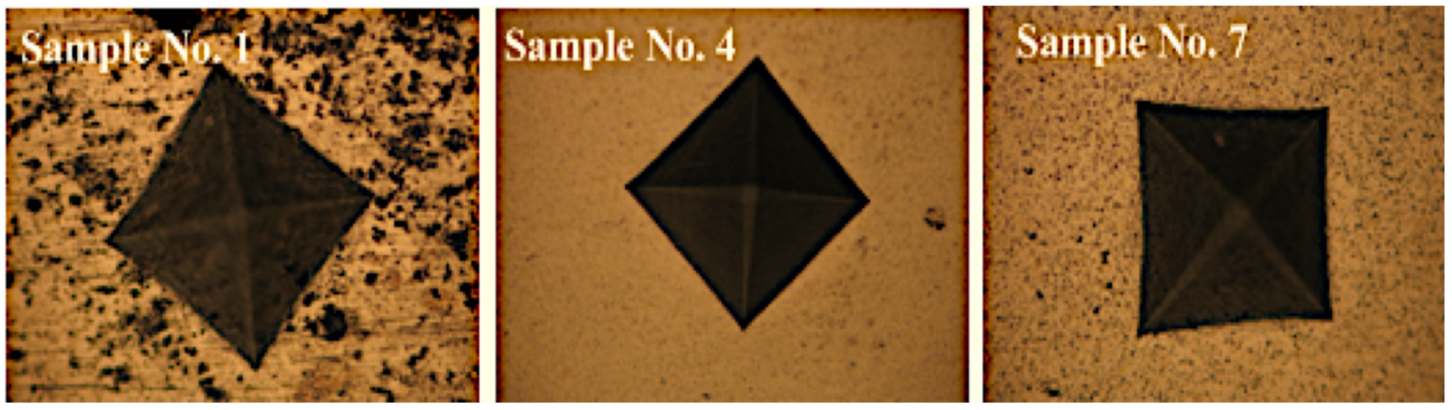

Figure 8. Hardness indentation of the investigated ODS reinforced tungsten heavy alloys (WHAs).

The verification experiment was conducted according to the optimized factors levels $A_{2} B_{3} C_{2} D_{3}$ by the Taguchi method. Three specimens were prepared under the above-mentioned optimal conditions. The hardness was measured to be $410.67 \mathrm{HV}$, which is in confidence interval of the predicted hardness (431.51 HV), where the difference between the predicted and verified was about $4.8 \%$.

\subsubsection{Compressive Strength of ODS Tungsten Heavy Alloys}

In this investigation, the compressive strength at specified strain rate $(\varepsilon=0.5)$ was determined for every sample in selected orthogonal array. The compressive strength results were analyzed according to (the bigger the better) the $\mathrm{S} / \mathrm{N}$ ratio.

It was observed from the values of the compressive strength presented in Table 2 and Figure 9 that the compressive strength of the samples increases by increasing the compaction pressure until $400 \mathrm{MPa}$ and then decreases at $600 \mathrm{MPa}$ because of increasing porosity. This increase in compressive strength is caused by increasing the density and lowering the porosity, as the reduction in effective cross-sectional area due to the pores is detrimental to the strength [22]. Additionally, the porosity is considered as crack initiation sites. Furthermore, the obtained response graph shows that as the temperature of sintering is raised from 1300 to $1400^{\circ} \mathrm{C}$, the compressive strength remarkably increases. However, the strength slightly decreases afterwards when the sintering temperature is increased to $1500{ }^{\circ} \mathrm{C}$, due to the tungsten grain growth in the produced samples during the liquid phase sintering.

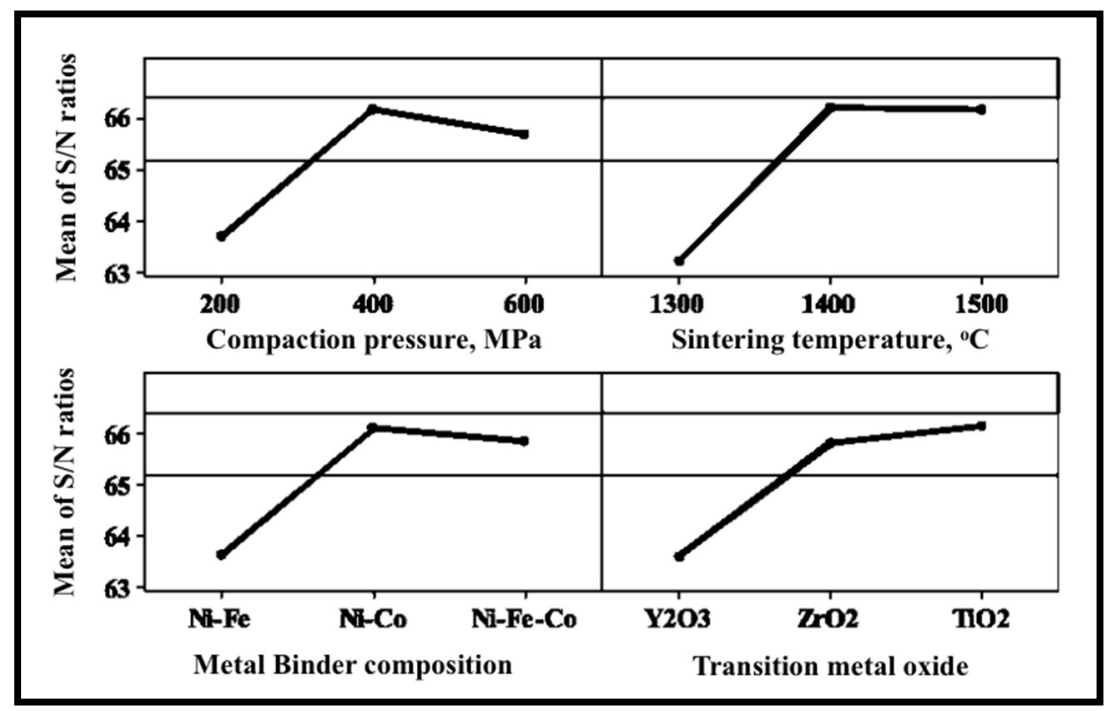

Figure 9. Mean of $\mathrm{S} / \mathrm{N}$ ratios for compressive strength of samples versus levels of input parameters.

The results also show that the compressive strength increases when $\mathrm{TiO}_{2}$ is used as reinforced particles. Oxide addition has a great effect on the mechanical properties of the tungsten alloys due to the refining of the microstructure, as discussed before. The oxide particles dispersed in the alloy work 
as pinning sights to hinder the movement of dislocations and improve the strength [4]. The optimal metal binding material shown through the results was Ni-Co. The presence of the Co element helps to improve the strength of the samples. The little additional amount of Co causes improvement in the strength and elongation of WHAs [26].

In addition, one can notice from Table 2 and Figure 9 that sample one has the smallest value of compressive strength as compared to the other samples. To clarify the results, SEM micrographs showing the fracture surface of samples one and five are indicated in Figure 10. It is well established that four fracture paths are possible for the heavy alloy microstructure: ductile phase failure, tungsten cleavage, tungsten inter-granular failure (failure along $\mathrm{W}-\mathrm{W}$ grain boundary) and tungsten-ductile phase interfacial separation $[2,15,27]$.
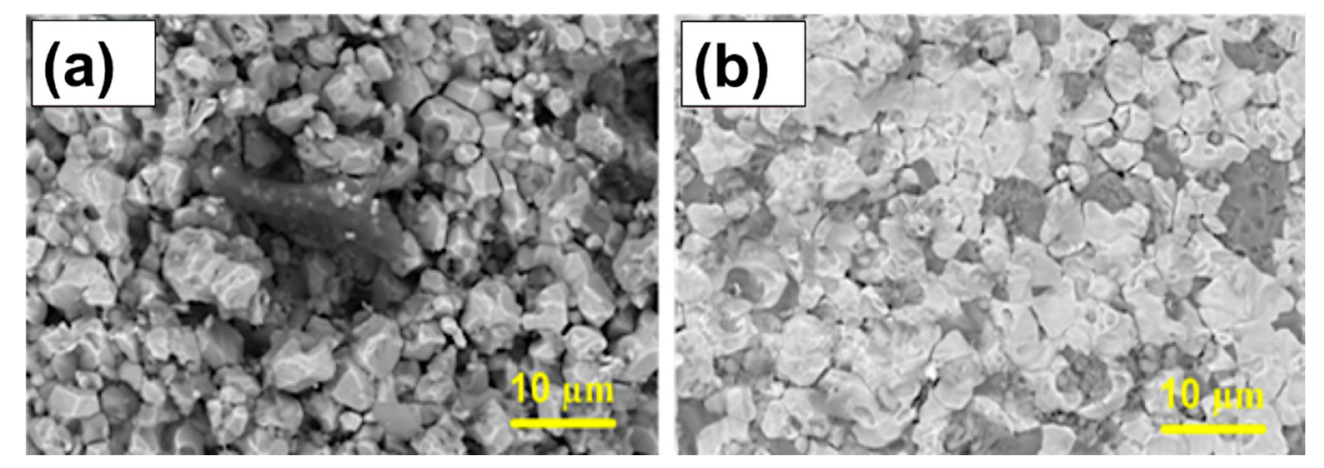

Figure 10. Fracture morphology of investigated samples: (a) sample no. (W-Ni-Fe- $\mathrm{Y}_{2} \mathrm{O}_{3}$ ) sintered at $1300{ }^{\circ} \mathrm{C}$ and (b) sample no. five (W- Ni-Fe-Co- $\left.\mathrm{Y}_{2} \mathrm{O}_{3}\right)$.

It can be shown from Figure 10 that both samples one and five show predominantly $\mathrm{W}-\mathrm{W}$ intergranular failure. These results confirm that the grain boundary between adjacent $\mathrm{W}$ grains is a weak interface as fracture surfaces for both samples show about the same value of failure stress by this path as reported in previous works [26-28]. The main reasons for reduction in compressive strength of sample one may be attributed due to the distribution of tungsten particles within the matrix. One can notice that sample one that was sintered at $1300^{\circ} \mathrm{C}$ (Figure 10a) shows inhomogeneous structure as a result of the presence of the big number of face to face $\mathrm{W}-\mathrm{W}$ globules, while the structure of sample five that was sintered at $1400{ }^{\circ} \mathrm{C}$ (Figure 10b) reveals the existence of metal binding material among the tungsten globules, forming uniform interconnected structure. The previous work on WHAs indicates that the formation of cracks in the tungsten alloy usually starts through interfaces between tungsten grains rather than through interfaces between $\mathrm{W}$-globules and the matrix phases. The ductile matrix is considered as an important obstacle to crack propagation [28]. Additionally, the alloy plasticity is improved by the higher amount of matrix phase between the harder W-grains and also by its uniform distribution. Increasing the sintering temperature strengthens the tungsten-matrix interfacial bond. Non-uniform distribution of the matrix phase and the existence of tungsten globule clusters of low plasticity usually lowers the strength of the alloy [24,29].

The optimal levels of the processing parameters to maximize compressive strength of ODS tungsten heavy alloys were determined from the response graph as $\mathrm{A}_{2} \mathrm{~B}_{2} \mathrm{C}_{2} \mathrm{D}_{3}$ by the Taguchi method. Hence, the expected average of compressive strength at the optimum condition was calculated as 2509.66 MPa. The verification experiment was conducted according to the optimized factor levels of $\mathrm{A}_{2} \mathrm{~B}_{2} \mathrm{C}_{2} \mathrm{D}_{3}$. The compressive strength is measured to be $2833 \mathrm{MPa}$. The difference between the predicted and verified value of compressive strength was obtained as $12.8 \%$.

In order to evaluate the experimental results at optimal conditions of the current investigation, there are a number of previous research works that deal with the physical and mechanical properties of WHAs and they were selected for comparison. The selected research work uses parameter levels in the same range of the applied one for the current investigation by the Taguchi method. Figure 11 shows 
the comparison of the measured properties of relative density, electrical conductivity, and hardness of this investigation with the other data $[3,5,13]$ from previous research works. However, there are no valuable data for compression strength at room temperature of WHAs in literature.

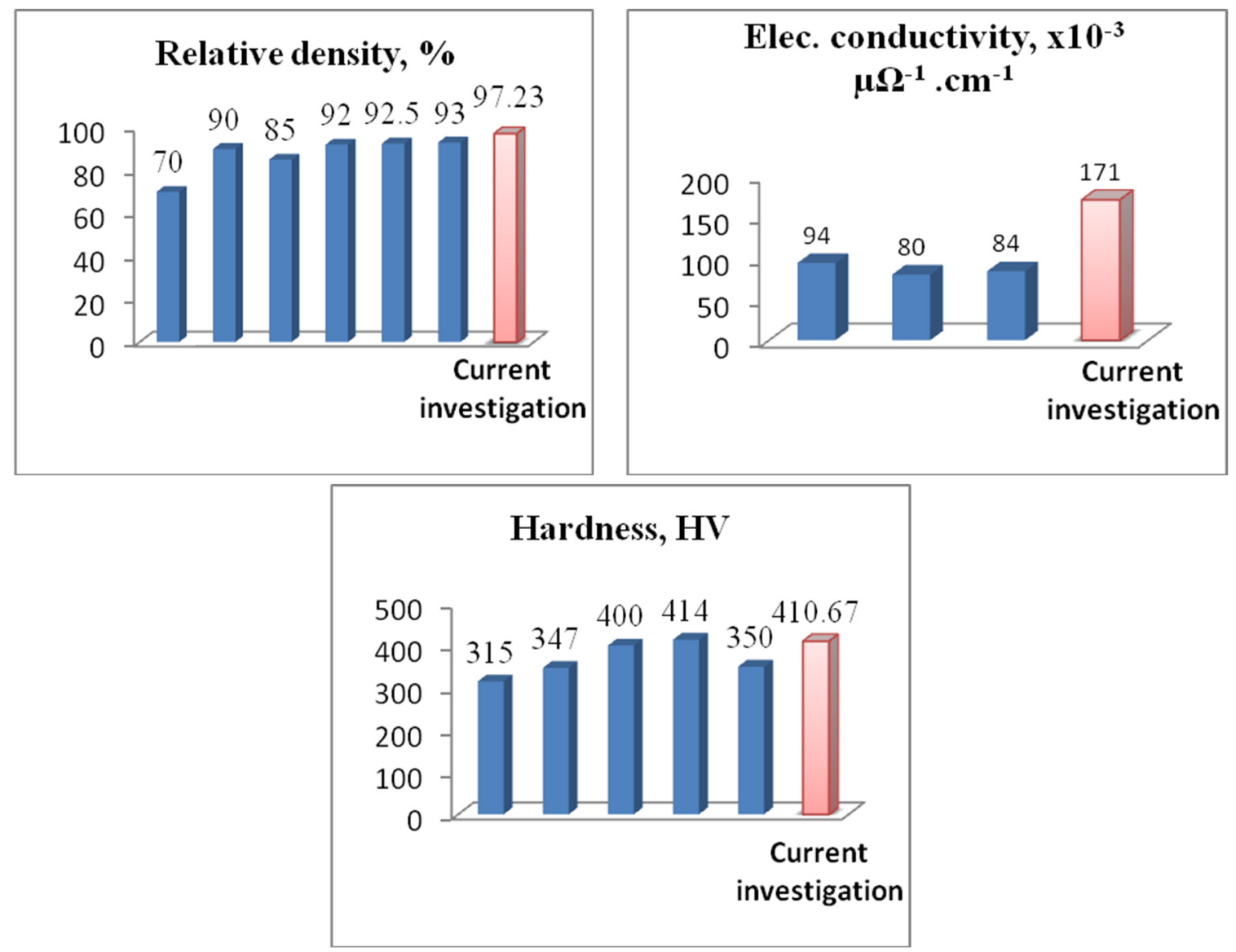

Figure 11. Comparison of the current investigation results with previous research results.

One can notice that the results of the obtained properties of this investigation for the ODS tungsten heavy alloys (W- $4.9 \mathrm{Ni}-1.05 \mathrm{Fe}-1.05 \mathrm{Co}-2 \mathrm{TiO}_{2}$ ) exhibit higher relative density (about $4.73 \%$ more than the larger value in previous literatures). Additionally, the electrical conductivity of ODS tungsten heavy alloys (W- $4.9 \mathrm{Ni}-2.1 \mathrm{Co}-2 \mathrm{TiO}_{2}$ ) that were obtained in this investigation seem to be double the larger value obtained in the compared research work. The value of the hardness of this investigation seems to be close to literature values, and Figure 11 summarizes the data for comparison.

\section{Conclusions}

The present work aims at finding out the effect of four parameters: compaction pressure, sintering temperature, composition of metal binder phase and the type of transition metal oxide on the properties of oxide dispersing strengthening (ODS) tungsten heavy alloys using the Taguchi method as the parameter optimizing method. The main points of the current research can be summarized as follows:

The density of ODS tungsten heavy alloys is affected by all of the four processing parameters (i.e., compaction pressure, sintering temperature, composition of the metal binder phase and the type of the transition metal oxide). It can also be found that the type of transition metal oxide has higher effect of $60.18 \%$ change of the sintered density than the other parameters; compaction pressure, sintering temperature and binding material type by, $25.87 \%, 4.43 \%$ and $2.88 \%$, respectively. 
The sintering temperature has a greater effect on the electrical conductivity of ODS WHA samples with $78.34 \%$ contribution, while other parameters e.g., compaction pressure $(8.57 \%)$, oxide type $(4.29 \%)$, and the composition of the metal binder phase $(2.5 \%)$ have comparatively smaller effects.

Among the four factors tested, it was concluded that the compaction pressure had the most significant effect on the hardness of ODS tungsten heavy alloys, while the composition of the metal binder phase had the next most significant effect.

From the comparison of the current investigation with respect to previous research work, it can be concluded that the addition of nanostructure $\mathrm{TiO}_{2}$ as reinforcement particles to the WHA provides new materials with higher density and electrical conductivity, which may be adequate in some applications such as kinetic energy penetrators. In addition, materials with higher electrical conductivity are required for electrical contact applications.

Author Contributions: Conceptualization, A.H.E., M.A.S., O.M.D. and W.M.D.; Methodology, A.H.E., M.A.S., O.M.D. and W.M.D.; software, A.H.E., M.A.S. and O.M.D.; validation, A.H.E., M.A.S., O.M.D. and W.M.D.; formal analysis, A.H.E., M.A.S., O.M.D. and W.M.D.; investigation, A.H.E., M.A.S. and W.M.D.; resources, A.H.E., and W.M.D.; writing-original draft preparation, A.H.E., M.A.S., O.M.D. and W.M.D., writing-review and editing, A.H.E., M.A.S. and W.M.D. All authors have read and agreed to the published version of the manuscript.

Funding: This research received no external funding.

Conflicts of Interest: The authors declare no conflict of interest.

\section{References}

1. Hafızo ğlu, H.; Durlu, N. Effect of sintering temperature on the high strain rate-deformation of tungsten heavy alloys. Int. J. Impact Eng. 2018, 121, 44-54. [CrossRef]

2. Majumdar, S.; Kishor, J.; Paul, B.; Kain, V. Densification behaviour, microstructural characteristics and mechanic al properties of liquid phase sintered W-2Ni-1Fe alloy. J. Alloys Compd. 2020, 818, 1-8. [CrossRef]

3. Abdel Hamid, Z.; Moustafa, S.F.; Daoush, W.M.; Abdel Mouez, F.; Hassan, M. Fabrication and Characterization of Tungsten Heavy Alloys Using Chemical Reduction and Mechanical Alloying Methods. Open J. Appl. Sci. 2013, 3, 15-27. [CrossRef]

4. Jingang, Z.; Weimin, W.; Wei, J.; Kai, Y. Ultrafie Grain Tungsten Heavy Alloys with Excellent Performance Prepared by Spark Plasma Sintering. J. Wuhan Univ. Technol. Mater. Sci. Ed. 2020, 735, 393-398. Available online: www.jwutms.net (accessed on 16 September 2020).

5. Chen, C.L.; Huang, C.L. Milling Media and Alloying Effects on Synthesis and Characteristics of Mechanically Alloyed ODS Heavy Tungsten Alloys. Int. J. Refract. Met. Hard Mater. 2014, 44, 19-26. [CrossRef]

6. Prabhu, G.; Arockia Kumar, R.; Nandy, T.K. Effct of Yttrium Oxide Dispersion on the Microstructure and Properties of Tungsten Heavy Alloys. Def. Sci. J. 2018, 68, 406-411.

7. Senthilnathan, N.; Raja Annamalai, A.; Venkatachalam, G. Microstructure and mechanical properties of spark plasma sintered tungsten heavy alloys. Mater. Sci. Eng. A 2018, 710, 66-73. [CrossRef]

8. Chen, C.; Huang, C.; Zeng, Y. Synthesis of ODS heavy tungsten alloys through post-annealing and secondary ball milling. Int. J. Refract. Met. Hard Mater. 2015, 48, 359-364. [CrossRef]

9. Daoush, W.M.; El Sayed, A.H.; El Kady, O.A.; Sayed, M.A. Enhancement of Physical and Mechanical Properties of Oxide Dispersion Strengthened Tungsten Heavy Alloys. Metall. Mater. Trans. A 2016, 47, 2387-2395. [CrossRef]

10. Chen, C.H.; Sutrisna. The Effect of Mo and Dispersoids on Microstructure, Sintering Behavior, and Mechanical Properties of W-Mo-Ni-Fe-Co Heavy Tungsten Alloys. Metals 2019, 9, 111. [CrossRef]

11. Zhang, X.; Zhu, S.; Zhang, B.; Ahmad, T.; Wang, C.; Zhou, L.; Liang, T.; Yang, B. Effect of $\mathrm{Y}_{2} \mathrm{O}_{3}$ Addition on the Microstructure, Wear Resistance, and Corrosion Behavior of $\mathrm{W}_{-4.9} \mathrm{Ni}_{-2.1}$ Fe Heavy Alloy. J. Mater. Eng. Perform. 2019, 28, 4801-4810. [CrossRef]

12. Sayed, M.A.; Dawood, O.M.; EL Sayed, A.H.; Daoush, W.M. Application of Taguchi Method in Optimization of Process Parameters of ODS WHAs. Adv. Mater. Res. 2017, 6, 79-91. [CrossRef]

13. Veleva, L. Contribution to the Production and Characterization of W-Y, W- $Y_{2} \mathrm{O}_{3}$ and $\mathrm{W}$-TiC Materials for Fusion Reactors. Dr. Philos. 2011, 1-164. [CrossRef] 
14. Akhtar, F. An Investigation on the Solid State Sintering of Mechanically Alloyed Nano-Structured 90W-Ni-Fe Tungsten Heavy Alloy. Int. J. Refract. Met. Hard Mater. 2008, 26, 145-151. [CrossRef]

15. Wu, Y.; German, R.M.; Marx, B.; Bollina, R.; Bell, M. Characteristics of Densification and Distortion of Ni/Cu liquid-phase sintered tungsten heavy alloy. Mater. Sci. Eng. 2003, 344, 158-167. [CrossRef]

16. Eliasson, A. Liquid Phase Sintering of W-Ni-Fe Composites-Initial Melt Penetration, Agglomerate Separation and Particle Interaction; Trita-MG AVH; KTH: Stockholm, Sweden, 2006; pp. 1-15.

17. Zhu, Y.B.; Wang, Y.; Zhang, X.Y.; Qin, G.W. W/NiFe Phase Interfacial Characteristics of Liquid-Phase Sintered W-Ni-Fe Alloy. Int. J. Refract. Met. Hard Mater. 2007, 25, 275-279. [CrossRef]

18. Bollina, R.; German, R.M. Heating Rate Effects on Microstructural Properties of Liquid Phase Sintered Tungsten Heavy Alloys. Int. J. Refract. Met. Hard Mater. 2004, 22, 117-127. [CrossRef]

19. Kunčická, L.; Kocich, R.; Klečková, Z. Effects of Sintering Conditions on Structures and Properties of Sintered Tungsten Heavy Alloy. Mater. 2020, 13, 2338. [CrossRef]

20. Otto, K.N.; Antonsson, E.K. Extensions to the Taguchi Method of Product Design. ASME J. Mech. Des. 1993, 115, 5-13. [CrossRef]

21. Ekbom, L.; Antonsson, T. Tungsten Heavy Alloy: Deformation Texture and Recrystallization of Tungsten Particles. Int. J. Refract. Met. Hard Mater. 2002, 20, 375-379. [CrossRef]

22. Ibrahim, A.; Abdallah, M.; Mostafa, S.F.; Hegazy, A.A. An Experimental Investigation on the W-Cu Composites. Mater. Des. 2009, 30, 1398-1403. [CrossRef]

23. Kamaruddin, S.; Khan, Z.A.; Foong, S.H. Application of Taguchi Method in the Optimization of Injection Moulding Parameters for Manufacturing Products from Plastic Blend. Int. J. Eng. Technol. 2010, 2, 574-580. [CrossRef]

24. Upadhyaya, G.S. Powder Metallurgy Technology; Cambridge International Science Publishing: Cambridge, UK, 2002.

25. Callister, W.D. Fundamentals of Materials Science and Engineering, 5th ed.; John Wiley and Sons Inc.: New York, NY, USA, 2001.

26. Das, J.; Ravi Kiran, U.; Chakraborty, A.; Eswara Prasad, N. Hardness and Tensile Properties of Tungsten Based Heavy Alloys Prepared by Liquid Phase Sintering Technique. Int. J. Refract. Met. Hard Mater. 2009, 27, 577-583. [CrossRef]

27. Islam, S.H.; Akhtar, F.; Askari, S.J.; Jokhio, M.T.; Qu, X. Tensile Behavior Change Depending on the Varying Tungsten Content of W-Ni-Fe Alloys. Int. J. Refract. Met. Hard Mater. 2007, 25, 380-385.

28. Hong, S.H.; Ryu, H.J.; Baek, W.H. Matrix Pools in a Partially Mechanically Alloyed Tungsten Heavy Alloy for Localized Shear Deformation. Mater. Sci. Eng. A 2002, 333, 187-192. [CrossRef]

29. Gero, R.; Borukhin, L.; Pikus, I. Some Structural Effects of Plastic Deformation on Tungsten Heavy Metal Alloys. Mater. Sci. Eng. A 2001, 302, 162-167. [CrossRef] 